Revista lus et Praxis, Año 25, № 1, 2019, pp. 383 - 414

ISSN 0717 - 2877

Universidad de Talca - Facultad de Ciencias Jurídicas y Sociales

El contrato y el derecho aplicable como dispositivos para la resolución

de los conflictos en el arbitraje internacional

M. Fernanda Vásquez Palma - Álvaro Vidal Olivares

Trabajo recibido el 28 de marzo de 2018 y aprobado el 28 de noviembre de 2018

\title{
El contrato y el derecho aplicable como dispositivos para la resolución de los conflictos en el arbitraje internacional*
}

\author{
THE CONTRACT AND THE APPLICABLE LAW AS INSTRUMENTS \\ OF CONFLICT RESOLUTION IN INTERNATIONAL ARBITRATION
}

\author{
M. Fernanda Vásquez Palma* \\ Álvaro Vidal Olivares ${ }^{* * *}$
}

\begin{abstract}
RESUMEN
La resolución de una controversia contractual exige al juez o árbitro que conoce de ella, la labor de observar las estipulaciones del contrato y determinar las normas de fondo que regirán el conflicto, lo que le obligará a realizar una labor de construcción de la regla contractual. Lo anterior será el fundamento conforme con el cual el juez o árbitro acogerá o rechazará la pretensión objeto del juicio respectivo. En cuanto al contenido del contrato debemos distinguir la voluntad expresada por las partes por medio de sus estipulaciones, las prácticas, y usos del comercio incorporados por aplicación del principio de la buena fe, y además las normas aplicables que se superponen, integran o suplen los vacíos de esa voluntad debidamente interpretadas.
\end{abstract}

\section{ABSTRACT}

The resolution of a contractual dispute requires the judge or arbitrator who knows about it the task of observing the stipulations of the contract and determining the substantive rules that will govern the conflict, which will force him to perform a task of constructing the contractual rule. The foregoing will be the basis in accordance with which the judge or arbitrator will accept or reject the claim object of the respective judgment. Regarding the content of the contract, we must distinguish the will expressed by the parties through its stipulations, the practices and uses of commerce incorporated by application of the principle of good faith, and also the applicable rules that overlap, integrate or supplement the gaps of that will.

Palabras Clave

Contrato, normas aplicables, arbitraje internacional

KEY WORDS

Contract, applicable law, international arbitration

\footnotetext{
* Este trabajo forma parte de los resultados del Proyecto Anillo sobre Mecanismos Alternativos de Solución de conflictos, como herramienta de modernización de la justicia. construcción dogmática a partir de un análisis multidisciplinario". SOC 1406, financiado por Conicyt Chile.

** Profesora de Derecho Privado, Universidad de Talca, Doctora en Derecho por la Universidad Complutense de Madrid, España, correo electrónico: mfvasquez@utalca.cl.

*** Profesor de Derecho Civil, Pontificia Universidad Católica de Valparaíso, Doctor en Derecho por la Universidad Autónoma de Madrid, España, correo electrónico: alvaro.vidal@pucv.cl.
} 


\section{Presentación}

La resolución de una controversia contractual exige al juez o árbitro que conoce de ella, la labor de develar lo pactado en el contrato y las normas que regirán el conflicto, lo que le obligará a realizar un trabajo de disección de fuentes, en pos de indagar la o las leyes a las que se sometieron las partes en el contrato o, en su defecto, las que correspondan aplicar, pues ellas serán el fundamento conforme con el cual se acogerá o rechazará la pretensión objeto del juicio respectivo.

A partir de estos elementos podremos construir la regla contractual como dispositivo de solución de conflictos, la que presenta especiales ingredientes a considerar. Llegaremos a ella incursionado en el contenido del contrato y advirtiendo la voluntad expresada por las partes por medio de sus estipulaciones, prácticas y usos del comercio incorporados por aplicación del principio de la buena fe, y las normas aplicables que integran o suplen los vacíos de esa voluntad, debidamente interpretadas ${ }^{1}$.

El contrato, en cuanto regla ${ }^{2}$, representa un instrumento de previsión, no sólo para la realización de la prestación -objeto ideal-, sino también para el evento que lo ejecutado por el deudor -objeto real (cosa o hecho)- no se adecue a aquélla comprometida inicialmente. En otras palabras, el contrato prevé tanto para el cumplimiento como para el incumplimiento: prestación debida y remedios del acreedor ${ }^{3}$.

Ahora bien, cuando pensamos en un conflicto referido a los efectos de un contrato de carácter internacional, y especialmente de uno referido a una compraventa internacional de mercaderías sometida a la Convención de Viena que rige la materia (CISG), en el que las partes decidieron incorporar un contrato arbitral, afloran ciertas incertidumbres que nos obligan a incursionar y diseccionar diversas aristas, con la finalidad de vislumbrar la construcción de la regla contractual sobre la que se decidirá el conflicto. Esta conjunción

\footnotetext{
1 Vidal define la regla contractual como "el conjunto normativo conformado por las normas imperativas de necesaria aplicación, (sic) declaración negocial (que presupone la interpretación de la voluntad de las partes), debidamente integrada por las fuentes dispositivas". VIDAL (2000), pp. 211 y 219.

2 De Castro y Bravo, reconociendo en el contrato una regla a la que se someten las partes, afirma que: "se puede afirmar sin dificultad que el negocio tiene una doble eficacia: a) (sic) la de título de una serie de derechos, facultades, obligaciones y cargas, o, expresado de otro modo, de fundamento de una relación jurídica, de creador de una nueva realidad jurídica; b) (sic) la de establecer una regla, con la que se mide la conducta de autorizados y obligados (lo permitido, lo debido, el incumplimiento); lo que se ha designado con el término sugestivo, aunque equívoco, de significado 'preceptivo' del negocio". De Castro y Bravo (1985), p. 32.

${ }^{3}$ VIDAL (2014), pp. 711-742.
} 
provoca que el supuesto inicial torne especialmente interesante y justifique el presente análisis.

El sistema arbitral internacional que resolverá el conflicto, será aquel que las partes escojan, pudiendo situarse en normas procesales institucionales o estatales. En ambos casos, las partes elegirán la sede arbitral y ésta proveerá el marco normativo aplicable, junto a los tribunales estatales que servirán de soporte y control. La mayoría de las leyes arbitrales internacionales siguen, en la actualidad, a la Ley Modelo sobre arbitraje comercial internacional Uncitral/Cnudmi, dictada en 1986 y modificada en el año 2006. Esta ley, adaptada por los distintos Estados, fija las reglas que, a falta de una voluntad contraria de los contratantes, regirá el juicio, junto con prever la posibilidad de que las partes decidan las normas de fondo conforme con las cuales el árbitro resolverá el conflicto. La Lex arbitri constituye el marco jurídico que debemos necesariamente considerar pues aquél se pronuncia sobre la internacionalidad, el contrato arbitral, la ley de fondo aplicable en defecto de la voluntad de las partes y las causales de nulidad del laudo, junto a algunas leyes aplicables a estos efectos.

Derivado de lo anterior, las preguntas que guían este trabajo son las siguientes: ¿Cómo debe construir el árbitro la regla contractual en un conflicto que nace de una compraventa internacional de mercaderías?, ¿qué elementos debe considerar a estos efectos? y ¿cuál es la importancia y trascendencia de esta elección?

En nuestra opinión, la regla contractual constituye un dispositivo eficiente para la resolución de un conflicto arbitral, siempre que en su construcción se consideren todos los elementos necesarios. Esta afirmación se inscribe en ciertas premisas, como son: 1. Que para resolver el conflicto el árbitro debe discernir las leyes aplicables al contrato arbitral, al contrato objeto del litigio, al fondo del asunto debatido y a las normas procesales que guían el arbitraje; 2. que en dicho trabajo el árbitro debe considerar las normas que se superponen o complementan al contrato; 3 . que en un contrato de compraventa internacional de mercaderías, la CISG debe entenderse como una de las leyes a considerar y esta debe integrarse con los principios Unidroit.

Con la finalidad de dar respuesta a los interrogantes e ilustrar las premisas antes planteadas, compartiremos un caso de entrega no conforme en una compraventa internacional sometida a la CISG, para luego precisar las normas con arreglo a las cuales el árbitro que conozca del asunto deberá resolver el conflicto, dando cuenta de las distintas fuentes que han de considerarse y conciliarse: las estipulaciones contractuales, la ley de arbitraje, la ley aplicable al contrato arbitral, la ley aplicable al fondo del litigio y la CISG que gobierna este tipo contractual. 


\section{El caso}

El caso que ilustra el objeto del presente artículo, versa sobre un contrato de compraventa internacional de mercaderías en el que las partes incorporaron un acuerdo arbitral por el que sometieron todos los conflictos presentes o futuros que surjan de dicho contrato, al conocimiento de la justicia arbitral. En la cláusula arbitral a la que hicimos mención, los contratantes convinieron que el arbitraje se llevaría a cabo en Madrid por el árbitro designado al efecto.

Primeramente, digamos algunas cosas sobre el contrato de compraventa y sus condiciones. Las partes tenían sus establecimientos en Estados diversos; el vendedor en Chile y el comprador en España. El contrato tenía por objeto la entrega de fruta fresca de temporada de una calidad determinada que debía ser entregada en la condición pactada. Según las estipulaciones de contrato, el vendedor estaba obligado a concertar el transporte marítimo de las mercaderías hasta puerto de destino (entrega CIF Vigo - España). En cumplimiento de su obligación de entrega, el vendedor depositó la fruta objeto del contrato en los recintos portuarios de la ciudad de San Antonio, en contenedores refrigerados -observando las prácticas y usos del sector agrícola-, para que posteriormente fuera trasladada por el porteador -contratado por el vendedor- al puerto de destino en España. Debido a una huelga de los trabajadores portuarios, el transportista se vio impedido de retirar oportunamente los contenedores para su embarque. Ello sólo logró hacerlo transcurridos 10 días desde el depósito de la fruta en el puerto, en circunstancias que, considerando la calidad de la fruta y lo pactado con el comprador, el embarque debía tener lugar transcurridos tres días desde su depósito en los aludidos recintos. Finalmente, el transportista, luego de superar el impedimento que le afectó, traslada las mercaderías hasta el puerto de destino, produciéndose su entrega tardía al comprador.

Como consecuencia del retardo en la entrega -depósito, embarque y trasporte-, la fruta perdió la condición convenida, resultando no conforme con el contrato. El comprador español, al recibir las mercaderías las examinó inmediatamente, comunicando a su vendedor que las frutas padecían de anomalías materiales que las inhabilitan para su propósito contractual, razón por la cual las rechazó, exigiéndole otras en sustitución, esta vez conformes con el contrato. El vendedor se negó a tal requerimiento aduciendo que la sustitución le implicaba costos excesivos o desproporcionados. El comprador, insatisfecho con la situación, dio inicio al juicio arbitral requiriendo el cumplimiento específico del contrato de acuerdo al artículo 46 (3) CISG.

$\mathrm{Ni}$ en este pacto, ni en ninguno otro las partes se pronunciaron sobre las normas aplicables al litigio. 


\section{Las preguntas}

Para resolver este caso de disconformidad material de las mercaderías, debemos dar respuesta a algunas preguntas: 1. ¿Quién resuelve el conflicto?; 2. ¿con base en qué normas resolverá el litigio?; y 3. ¿cuál es el rol que le cabe a la CISG en la resolución del conflicto planteado?

La respuesta al primer interrogante nos obliga a recurrir al contrato. En él encontramos una cláusula muy escueta que se limita a declarar que: "Cualquier controversia que surja de este contrato será sometida a un arbitraje que se desarrollará en la ciudad de Madrid-España". Esta última declaración es relevante para determinar que la sede de arbitraje se encontrará en dicho lugar (art. 20 de la Ley Modelo) ${ }^{4}$ lo que, al mismo tiempo, determinaría que el arbitraje se regiría por la lex arbitri española.

En lo que concierne al segundo interrogante que suscita el caso, habremos de distinguir dos tipos de normas: procesales y sustantivas. Las procesales las encontraremos en la ley que rige el arbitraje, salvo que las partes modifiquen la normativa y dibujen un nuevo procedimiento conforme al cual se desenvolverá el arbitraje hasta la dictación del laudo. La lex arbitri pasa a ser, de este modo, una norma supletoria de la voluntad de los contratantes, ahora partes del juicio arbitral. En relación con las normas de fondo o sustantivas, deberemos distinguir entre la ley del contrato arbitral, la ley que rige el contrato del cual emerge el conflicto, y la ley que rige el fondo del asunto o litigio, todas podrían ser distintas y deben ser consideradas en la resolución del caso, lo que requerirá la determinación de su exacta aplicación y jerarquización.

La respuesta al tercero de los interrogantes planteados está estrechamente vinculada con la respuesta anterior, desde que la CISG, por un lado, da reglas de interpretación de la declaración de las partes (arts. 8 y 9); y por otro, junto con representar el derecho dispositivo o supletorio de tal declaración (art. 6), prevé un sistema de fuentes para la integración de sus vacíos o lagunas (art. 7). Veremos con detención lo antes expresado.

\section{III. ¿Quién resuelve el conflicto y cómo debe procederse?}

Como señalamos, en el contrato de compraventa existe una cláusula que indica que cualquier controversia que surja de aquél será sometida a un arbitraje que se desarrollará en la ciudad de Madrid. De aquélla se desprende que las partes han acordado, por medio de un contrato arbitral, someterse

\footnotetext{
${ }^{4}$ Sobre las sedes de arbitraje, VÁsquez (2011), pp. 77-137; Fernández (2007), pp. 25-62.
} 
a un arbitraje. Nada se señala sobre el tipo de arbitraje, de los árbitros que tendrán tal misión, ni de las normas aplicables, de manera que habremos de desentrañar estos tópicos.

Se trata de un contrato arbitral que toma la modalidad de una cláusula. En su interpretación deberán considerarse los principios que nutren tal acuerdo, como son el principio de separabilidad y el principio Kompetenz-Kompetenz; el primero implica que si el contrato en que se inserta es nulo o ineficaz, ello de ninguna manera afectará al contrato arbitral en tanto éste se entiende de forma independiente, el segundo se refiere a la posibilidad de que sea el propio árbitro quien resuelva las alegaciones sobre su propia competencia. Asimismo, debemos considerar que este contrato goza de un efecto positivo que se traduce en su fuerza obligatoria para ambos contratantes, y negativo, en cuanto los tribunales estatales estarán impedidos de conocer del conflicto debiendo remitir a las partes a este arbitraje a más tardar al momento en que uno de ellos oponga la excepción respectiva ${ }^{5}$.

Para determinar el tipo de arbitraje, deberemos discernir la ley aplicable al mismo, siendo relevante calificar si el caso si se enmarca en los criterios de internacionalidad previstos ${ }^{6}$. Desde el punto de vista del Derecho internacional privado clásico, la internacionalidad de una controversia o de una relación jurídica es el presupuesto esencial para plantearse la cuestión del Derecho aplicable o conflicto de leyes ${ }^{7}$. La determinación de los criterios sobre la internacionalidad del arbitraje no es unívoca y en absoluto puede considerarse una materia baladí a la hora de determinar la ley aplicable al fondo de la controversia. Así, en un arbitraje que deba desarrollarse en España, la mera elección de una ley aplicable al fondo por las partes, distinta al Derecho español, no resulta admisible si no se dan los criterios de internacionalidad previstos en el artículo $3^{\circ}$.

\footnotetext{
5 Silva et al. (2008), pp. 50-65; VÁsquez (2017), pp. 131-140.

${ }^{6}$ Ley de arbitraje $\mathrm{N}^{\circ}$ 60/2003 de 2003.

7 La internacionalidad del arbitraje puede obedecer a razones muy diversas, como acredita el artículo $1.3^{\circ}$ de la Ley Modelo Uncitral sobre Arbitraje Comercial Internacional: establecimiento de las partes en distintos Estados; lugar del arbitraje; lugar de ejecución del contrato o lugar de mayor vinculación del contrato, ubicados en un Estado diferente del domicilio de las partes; el propio acuerdo de las partes acerca de la internacionalidad del arbitraje. En otros sistemas jurídicos, la «internacionalidad» se hace depender de criterios tan abiertos como que la controversia afecte "a los intereses del comercio internacional" (art. 1.492 del Code de la procédure civile en Francia).
}

8 SÁNCHEZ (2009). 
Por otra parte, la lex arbitri que rige el procedimiento no implica de forma alguna que esa misma ley deba regir el contrato arbitral o el fondo del asunto, aun en defecto de voluntad de las partes, tal como veremos más adelante.

De acuerdo con la redacción de la cláusula, el arbitraje debe entenderse de derecho, pues las partes no declaran que este será en equidad, de manera que el árbitro ha de atenerse a las leyes aplicables. Ahora bien, dado que las partes no designaron al árbitro o tribunal arbitral en el contrato, éstas podrán hacerlo una vez que surja el conflicto, desarrollando o complementado la cláusula arbitral a estos efectos. Si no logran ponerse de acuerdo, podrán acudir a un centro arbitral o a los tribunales estatales españoles para que lo designe, desplegando lo que se conoce como "función de apoyo" a la justicia arbitral ${ }^{9}$.

\section{Determinación de las leyes aplicables al contrato arbitral, al fondo del conflicto y al procedimiento}

\section{Contextualización preliminar: ¿Qué derechos se aplican en un arbitraje internacional?}

La trama arbitral se descompone en fases y elementos, sustantivos y adjetivos, directamente conectados entre sí. Dentro de esta vasta y compleja operación, la convención o contrato arbitral es susceptible de amalgamar elementos de diversa procedencia.

La determinación del derecho aplicable al arbitraje ha girado en torno a tres problemas considerados como fundamentales ${ }^{10}$. En primer lugar, si se ha de aplicar una ley única a todo el arbitraje, y por consiguiente ha de ser una misma ley la que se aplique al contrato, al procedimiento y al laudo, o por el contrario debe concurrir una diversidad de leyes que disciplinen cada uno de los elementos constitutivos de la operación arbitral; luego, conocer qué conexión se erige con mayores méritos para regir el convenio arbitral; y finalmente, si la ley debe ser nacional o por el contrario puede consistir en una norma no nacional, desvinculando al máximo el arbitraje de los marcos jurídicos estatales y propiciando la consagración y el ejercicio sin límites de la autonomía de la voluntad.

Respecto del primer problema, la pregunta de si ha de aplicarse una sola ley a todo el arbitraje, incluyendo al convenio arbitral, no tiene una respuesta unívoca, dependerá de lo que establezca el sistema respectivo. Ante la ausencia

9 Sobre el tema, puede consultarse: López de Argumedo (2011).

10 Merino (2002). 
de una definición, lo más complejo será determinar con arreglo a qué criterios debe desentrañarse dicha ley, pues si bien sabemos que el arbitraje internacional acusa cada vez más una tendencia por desvincularse de los ordenamientos nacionales, sigue siendo frecuente que se aplique un derecho nacional o una combinación de normas con elementos internacionales.

Para dimensionar esta situación, debemos considerar que el contrato arbitral tiene por función conferir competencia a un tribunal arbitral con el objeto de que resuelva las controversias que surjan de una relación contractual o no contractual. Si nos encontramos en la primera hipótesis, hemos de determinar dos derechos distintos: el aplicable al contrato arbitral y el aplicable al contrato del cual emerge el conflicto. En ambos casos se recoge el principio general de la autonomía de la voluntad, que cumple dos roles bien definidos: uno material, o determinación de los contenidos contractuales ${ }^{11}$; y otro conflictual, de elección de ley de fondo aplicable en caso de controversia ${ }^{12}$. El primero reconoce a los contratantes el poder de configurar el contenido del contrato, reconociéndose expresamente su carácter de norma dispositiva ${ }^{13}$; en cambio, el segundo, permite a las partes elegir la ley aplicable al contrato ${ }^{14}$.

Si las partes nada expresan sobre el particular, las dudas serán los criterios que han de primar para su determinación, pues normalmente las leyes guardan silencio sobre este punto. De este modo, no podemos afirmar que exista un único derecho a considerar; son varias las normas potencialmente aplicables a los distintos elementos y todas ellas deben ser consideradas por el juez árbitro al momento de resolver el litigio, resguardando la validez de su sentencia.

\section{Ley aplicable al contrato arbitral}

La Ley Modelo no define qué ley debe regir el contrato arbitral, aquella solo regula algunos elementos relativos a la noción de arbitrabilidad, internacionalidad y el principio de escrituración del pacto arbitral; sin embargo, si analizamos las causales de nulidad y ejecución del laudo arbitral, constataremos

\footnotetext{
11 Hemos de advertir que la plena vigencia del precepto del artículo $6^{\circ}$ refiere para algunos Estados signatarios y no para aquellos que, al ratificar la CISG, hicieron la reserva de su artículo 96 que establece como límite de la autonomía privada la intangibilidad del artículo 12. SCHWENZER y HACHEM (2016).

12 De Miguel (2011), p. 317.

13 Oviedo (2011), p. 44.

14 Sobre este punto, Oviedo (2011), p. 44, y sobre la materia en general, ver entre otros: Calvo (2009), pp. 60-61; Carrascosa (2009), pp. 119-123; Castellanos (2009), p. 56; Feldstein (1995), pp. 63-73; JacQuet et al. (2010), pp. 206-207; Leible (1999), pp. 217-220; Marella (2005), p. 224.
} 
que aquél puede ser anulado o no ejecutado si el contrato arbitral es nulo de acuerdo con la ley a que las partes lo sometieron y si nada se indica sobre el particular, en relación a la ley del Estado sede, de manera que esta última adquiere un rol relevante en esta materia. A partir de ello, se colige que las partes tienen total libertad para determinar la o las leyes por las cuales se regirá dicho contrato. En caso de no constar tal decisión, se deberá buscar la voluntad implícita de las partes, la cual ha de emanar de las disposiciones de la convención generadora de derechos y obligaciones. Si aquello no fuere posible, la norma establece que rige supletoriamente la ley del Estado sede, con los consiguientes problemas que ello presenta, pues, como sabemos, esta ley presenta un carácter procesal y constituye un ave de paso en el arbitraje internacional. Frente a ello, lo óptimo sería que la ley supletoria del contrato arbitral fuese coincidente con la ley de fondo aplicable al conflicto, con el objeto de resguardar una debida concordancia.

Por otra parte, uno de los interrogantes que emerge de esta norma dice relación con el alcance de la estipulación que hace primar el pacto entre las partes, respecto de la ley aplicable, por sobre la normativa del país sede del arbitraje, pues se trata de un asunto que no se encuentra resuelto.

En la práctica, la normativa aplicable a un acuerdo de arbitraje ha recibido a lo menos tres respuestas: la ley de la sede arbitral ${ }^{15}$, la ley sustantiva aplicable al fondo del conflicto $^{16}$, y una normativa nacional basada en los principios generales del derecho y la presunta intención de las partes ${ }^{17}$. Esta última solución no podría seguirse por las legislaciones que se inspiran en la ley modelo, pues ésta en su art. 34 se refiere a una ley. Ahora bien, mientras la tradición jurídica del civil law se inclina a entender que la elección tácita es inadmisible, debiendo primar la ley de la sede, los tribunales de los países del common law se han decantado por la solución contraria, pues aun cuando en un caso los tribunales ingleses resolvieron que la ley del país sede del arbitraje era aplicable al acuerdo arbitral ${ }^{18}$, se ha mantenido la tendencia de

\footnotetext{
15 Opción seguida en la Ley Modelo de 1985 (art. 34).

${ }^{16}$ Opción que podría seguirse si el contrato arbitral está incorporado en el contrato del que emerge el conflicto, previendo una ley en su conjunto, y no existe disposición que contraríe tal posibilidad.

17 Opción seguida por el derecho francés. Véase: BerGer (2006), pp. 150-175; VAN DEN BERG, Jan et al. (2007), pp. 301-334.

18 Court of Appeal, EWCA Civ. 638, 16 de mayo de 2012. Esta decisión estableció tres criterios para definir el derecho aplicable al acuerdo arbitral, uno en subsidio de otro: la elección explícita de las partes; la elección implícita de las partes; el derecho con el cual el acuerdo arbitral tiene la relación real más importante.
} 
concluir que la ley aplicable al acuerdo arbitral es la misma que regula el fondo del contrato ${ }^{19}$.

La determinación de esta ley tiene una notable trascendencia en el arbitraje, pues ella conferirá fuerza vinculante al acuerdo, fijará las condiciones de su existencia y validez; establecerá el marco imperativo del contrato; y suministrará los criterios de interpretación y régimen supletorio a la voluntad de las partes (cláusulas esenciales y de la naturaleza). Asimismo, reviste el estándar mínimo en la formación y contenido del contrato, a partir de lo cual pueden actuar las partes sobre la base de su autonomía de la voluntad. Las normas que establecen tales exigencias constituyen el núcleo de las normas de Derecho de obligaciones que revisten carácter imperativo y están destinadas a garantizar el respeto a los estándares mínimos en la formación y el contenido del contrato, previendo su invalidez en caso de importantes deficiencias (incapacidad, error, dolo, intimidación del consentimiento) o cuyo contenido es contrario a la ley, la moral o el orden público ${ }^{20}$.

Con todo, en muchos casos, no debe extrañar que la identificación de la ley del contrato pueda ser innecesaria, en particular, porque las normas relevantes de los diversos sistemas jurídicos implicados en la controversia resultan ser similares o conducen a resolver del mismo modo la cuestión controvertida. Esta circunstancia explica que con frecuencia en los laudos arbitrales no se identifique un ordenamiento estatal aplicable ${ }^{21}$. Las carencias de los ordenamientos estatales en la regulación de las modalidades contractuales arbitrales y del comercio internacional también favorecen la evolución en la dirección señalada.

\section{Ley de fondo aplicable al arbitraje}

La ley aplicable al fondo de una relación jurídica, específicamente en el ámbito de los contratos, cumple una triple función: en primer lugar, completiva para integrar las lagunas contractuales, como default rules; en segundo lugar, cumple una función interpretativa para determinar el sentido de los pactos o cláusulas ambiguas u oscuras; $y$, en tercer lugar, despliega una función restrictiva para anular las disposiciones de las partes contrarias a reglas de imperativo

\footnotetext{
19 English Commercial Court, EWHC 3702 (Comm), de 20 de diciembre de 2012.

20 La situación es distinta tratándose de normas imperativas que tienen por objeto realizar determinados intereses económicos, políticos o sociales (ordenación de mercado, control de exportaciones, protección de consumidores, etc.) que sí divergen significativamente según los países. Sobre el tema, anteriormente, pp. 260-261.

${ }^{21}$ Sobre la vaguedad de la lex mercatoria, su imprecisión y falta de generalidad, véase KASSIS (1984), pp. 561-576; LAGARDE (1987), pp. 125 y ss.
} 
cumplimiento o indisponibles. Esta distinción resulta crucial para resaltar el régimen diferencial de relaciones existente entre la autonomía material y la autonomía conflictual en el ámbito del arbitraje comercial internacional, y, más allá de ello, las relaciones que se generan entre los pactos, cláusulas del contrato y la ley aplicable en defecto de elección ${ }^{22}$.

Llegados a este punto, hemos de considerar que la ley que regirá el fondo del conflicto se encuentra un paso más adelante en la Ley Modelo Arbitral pues, a diferencia del caso anterior (ley del contrato arbitral), aquí se plantea una solución expresa sobre el particular. En efecto, el art. 28 de la Ley Modelo prescribe:

"1) El tribunal arbitral decidirá el litigio de conformidad con las normas de derecho elegidas por las partes como aplicables al fondo del litigio.

Se entenderá que toda indicación del derecho u ordenamiento jurídico de un Estado determinado se refiere, a menos que se exprese lo contrario, al derecho sustantivo de ese Estado y no a sus normas de conflicto de leyes.

2) Si las partes no indican la ley aplicable, el Tribunal arbitral aplicará la ley que determinen las normas del conflicto de leyes que estime aplicables al caso.

3) El Tribunal arbitral decidirá ex aequo et bono o como amigable componedor sólo si las partes le han autorizado expresamente a hacerlo así.

4) En todos los casos, el tribunal arbitral decidirá con arreglo a las estipulaciones del contrato y tendrá en cuenta los usos mercantiles aplicables al caso".

De acuerdo con esta norma, nuevamente son las partes quienes tienen la facultad de definir las normas que regulan el conflicto, pudiendo tratarse de normas estatales o no estatales. Nótese que en el caso de la ley del contrato, la ley modelo acuña la expresión "ley" (art. 34), mientras que en este caso se alude a "normas" lo que pudiera entenderse en términos más amplios, de manera que las partes podrían elegir una ley estatal sola o combinada con la aplicación de principios o la lex mercatoria, o derechamente estas últimas. La disposición aclara que toda indicación del derecho u ordenamiento jurídico de un Estado determinado se refiere, a menos que se exprese lo contrario, al derecho sustantivo de ese Estado y no a sus normas de conflicto de leyes.

22 SÁNCHez (2009), p. 25. 
Aquí subyacen varias preguntas: ¿Podríamos comprender que la ley de fondo engarza con la ley del contrato que rige la relación jurídica de la que emerge el conflicto?, si ello es así, y no existe un pronunciamiento expreso sobre el particular, ¿cómo zanjaremos este punto?, si no es posible desprender tal voluntad, ¿cómo debe llegar el árbitro a su determinación?

Si las partes han previsto una ley para regir el contrato, podrá entenderse que ésta será la que rige el fondo del asunto, sin embargo, si no existe forma de determinar esta norma, el árbitro deberá elegirla de acuerdo al sistema conflictual (ley modelo) o material (Ej. Ley española), dependiendo de lo que disponga la lex arbitri. Este último sistema, el material, posee algunas ventajas, pues además de ser directo -a diferencia del primero- habilita a los árbitros a la aplicación de una reglamentación jurídica no estatal, mientras que la mención de "normas de conflicto" nos aproxima a una nomenclatura que, en la mayoría de los sistemas nacionales, implica necesariamente la referencia a la ley de un Estado ${ }^{23}$, lo que dificulta la aplicación de los Principios Unidroit y los generales del derecho. Por otra parte, la selección directa por el árbitro de las normas materiales apropiadas puede evitar los problemas derivados de la función restrictiva de la lex causae, pues no cabe considerar como apropiadas, en modo alguno, normas que modifiquen o deroguen los pactos o cláusulas establecidos en el contrato ${ }^{24}$.

Debemos considerar que la escogencia de varias leyes aplicables a un mismo contrato (dépeçage), podría ser altamente inconveniente debido a los posibles conflictos que se pueden presentar entre ellas ${ }^{25}$. Asimismo, tampoco podría entenderse un contrato sin ley, pues es muy difícil que el contrato pueda actuar de forma autosuficiente o completa, previendo todas las contingencias, por más detallado que se encuentre ${ }^{26}$. La norma aplicable es básica para establecer su validez y eficacia.

En este orden de ideas, cuando las partes eligen la ley aplicable, un principio elemental de interpretación aconseja prescindir de la función restrictiva de la ley aplicable, pues no resulta razonable suponer que las partes no habrían elegido una ley que anule sus pactos, a menos que se deduzca claramente lo contrario. En muchos casos, la propia ley elegida puede contener esta

\footnotetext{
${ }^{23}$ Para determinar esta ley, suele acudirse a dos sistemas, uno flexible (vínculos más estrechos con el contrato) y otro más rígido (Ej. lugar donde se había celebrado el contrato, o el lugar o los lugares de ejecución del mismo.

${ }^{24}$ Véase art. 34 de la Ley de Arbitraje española 60/2003 de 2003.

${ }^{25}$ Esta teoría fue diseñada para los contratos mixtos o atípicos, es decir, un contrato que "reúne prestaciones u obligaciones provenientes de diferentes tipos de contratos". TALERO (2008), p. 348.

${ }^{26}$ Leible (2010), pp. 13-47.
} 
fórmula, así ocurriría en una hipotética elección de los Principios Unidroit como ley aplicable al contrato, pues salvando unas pocas disposiciones imperativas, las cláusulas del contrato que deroguen o modifiquen su contenido prevalecerán (art. 1.5).

En este contexto, adquieren un rol importante los principios generales del Derecho y los Principios Unidroit sobre contratos comerciales internacionales, los cuales establecen reglas generales que se aplican a los contratos mercantiles internacionales, y que entran a regir una convención, cuando las partes hayan acordado que su contrato se rija por ellos o no han escogido ley aplicable ${ }^{27}$. Pero, ¿cuándo el árbitro podrá aplicar estos principios? No hay consenso sobre esta materia, nosotros consideramos que ello solo sucederá cuando una cláusula expresa de determinación de la ley aplicable lo autorice o el árbitro, teniendo facultades (por ej. Sistema material), decide aplicarlos. En caso de conflicto entre derecho estatal y principios generales, la solución dependerá de la naturaleza del principio en cuestión, y de su lugar en la estructura del ordenamiento jurídico, en tal sentido, solo un principio internacional, por su origen y campo de aplicación, pareciera susceptible de primar por sobre el orden legal de un $\mathrm{Estado}^{28}$. A modo de ejemplo, parece recomendable recurrir al artículo 7.4.9 de los Principios para completar la laguna del Convenio de Viena de 1980 sobre el procedimiento de cálculo de los intereses previstos en el artículo 78. De hecho, buena parte de los laudos arbitrales que aplican los Principios Unidroit tienen por objeto la integración del Convenio de Viena, sin embargo, la utilización de sus disposiciones como base exclusiva de un fundamento jurídico, puede resultar muy arriesgada como ley global aplicable al contrato.

Se agrega en la norma transcrita que el tribunal siempre debe decidir conforme a las estipulaciones del contrato y tendrá en cuenta los usos mercantiles aplicables al caso. De este modo, el árbitro debe atender, en primer término, al contenido del contrato y a los pactos celebrados entre las partes ("En todo caso" art. 34.3\%).

En relación a las estipulaciones del contrato, la práctica internacional relativa a la redacción de contratos comerciales presenta un carácter dinámico y una continua adaptación a los cambios tecnológicos y empresariales. Se muestra además una cierta autonomía con respecto a las legislaciones nacionales, pues se observa una marcada tendencia de los operadores a desarrollar soluciones y reglas novedosas para dar respuesta a problemas

${ }^{27}$ Véase los laudos señalados por Bruno Oppetit. OpPetit (2006), pp. 201-205.

${ }^{28}$ OpPetit (2006), p. 208. 
prácticos, dentro del amplio alcance que los diversos ordenamientos atribuyen a la autonomía de la voluntad en el ámbito de los contratos mercantiles internacionales ${ }^{29}$. Se trata de contratos muy puntillosos que pretenden contemplar todos los aspectos relevantes, de manera que los contratantes, partiendo de que son quienes mejor conocen sus relaciones negociales, relegan el mínimo posible al impacto de la ley del contrato para colmar las posibles lagunas ${ }^{30}$. Con todo, la ley aplicable siempre será necesaria para deslindar su necesaria validez y eficacia, de manera que en la construcción de la regla contractual se obliga al árbitro a considerar los términos pactados y las leyes aplicables por sobre tal voluntad (imperativas) y las supletorias.

La elección de un Derecho estatal no excluye la eventual aplicación de textos como el Convenio de Viena de 1980 sobre compraventa internacional de mercancías, cuando dicho convenio forma parte de la lex causae y su aplicación proceda por razones materiales y espaciales. Para que ello no ocurra, tal como explicaremos más adelante, la aplicación del Convenio de Viena debe descartarse expresamente por las partes (opting out) si quieren evitar una aplicación de sus normas eventualmente contrarias a lo dispuesto en las disposiciones de la lex causae aplicables a situaciones internas. Lo relevante será determinar en qué medida es indicado aplicar las disposiciones del Convenio si son contradictorias con los propios pactos suscritos por las partes que, eventualmente, pueden alinearse con las disposiciones de la lex causae previstas para supuestos internos. Esta cuestión no debe recibir una respuesta distinta a la que procede si semejante contradicción se produce, con carácter general, entre la lex causae y los pactos establecidos por las partes ${ }^{31}$.

En cuanto a la aplicación de los usos internacionales, sectoriales o particulares, se entiende que éstos intervienen en la regulación del fondo de la controversia de forma muy similar a los propios acuerdos entre las partes, pues se observan como una suerte de acuerdo tácito entre ellas. Los usos comerciales sólo pueden ser invocados con función completiva, interpretativa o integradora, en el caso de lagunas de reglamentación o ambigüedad de los pactos contractuales. La general aceptación de los usos comerciales suele implicar un reconocimiento de su eficacia por los sistemas jurídicos, de forma que en la práctica la cuestión clave consistirá en determinar y acreditar dichos usos, y no en una eventual contradicción con normas imperativas del derecho aplicable. La compatibilidad se facilita a través del tenor de estos

${ }^{29}$ VÁsQuez (2017), pp. 10-20.

30 Fernández et al. (2005), pp. 255 y ss.

31 SÁnChez (2009), p. 30. 
mismos textos, así, el artículo 1.9 (2) de los Principios Unidroit explicita que "las partes están obligadas por cualquier uso que sea ampliamente conocido y regularmente observado en el comercio internacional por los sujetos participantes en el tráfico mercantil de que se trate, a menos que la aplicación de dicho uso sea irrazonable". Una vez constatado el uso comercial, éste viene a ser un término implícito del contrato equivalente a un pacto, razón por la cual prevalecerá sobre cualquier disposición contradictoria de los principios. Para la acreditación de un uso el árbitro puede recurrir a informes periciales, u otro tipo de probanzas.

Finalmente, hemos de considerar que, a diferencia de la ley del contrato arbitral, la ausencia de una revisión o control de fondo del laudo arbitral en la mayor parte de las legislaciones arbitrales modernas parecería excluir, a priori, una acción de anulación del laudo por incorrecta aplicación de la ley aplicable al fondo. No existe un motivo de anulación que pueda justificar una acción de anulación basada exclusiva y directamente en la correcta o incorrecta fundamentación jurídica del laudo; sin embargo, esto puede conectarse bajo determinadas circunstancias con otros motivos de anulación, esencialmente los referidos al incumplimiento del mandato fijado por las partes en el acuerdo arbitral, el respeto del principio contradictorio en el proceso, y, por supuesto, el orden público.

\section{Ley aplicable al procedimiento}

Tal como hemos expresado más atrás, la ley que regirá el procedimiento será la lex arbitri determinada por las partes o el árbitro en su defecto. Siguiendo la ley modelo, esta ley normalmente proveerá un sistema flexible de acuerdo al cual las partes tienen amplias posibilidades de modificar el procedimiento de acuerdo a su común voluntad, de forma que la ley en cuestión pasará a ser supletoria de aquélla.

Esta ley provee un marco procesal respecto de todas las actuaciones y principios arbitrales, junto con establecer el ámbito de aplicación material, la definición de contrato, la designación del tribunal arbitral, la posibilidad de dictar medidas cautelares, la ley aplicable al fondo del litigio, los requerimientos de la sentencia arbitral, así como del sistema recursivo y de inejecución que cabe en su contra. Asimismo, plantea cuáles serán los tribunales estatales de apoyo y de control que podrán interactuar en el procedimiento arbitral.

En la actualidad, gran parte de las legislaciones arbitrales siguen en este punto a la ley modelo arbitral Cnudmi/Uncitral, lo que ha dado paso a una armonización en la materia. Si no se da cumplimiento a lo dispuesto en esta ley, el laudo podría ser anulado de conformidad a las causales que ella misma contempla. 


\section{La regla contractual en la CISG.}

El caso analizado versa sobre una compraventa internacional de mercaderías, de modo que procede detenerse en la Convención de Viena que regula la materia, pues esta norma es la comúnmente aplicable a los contratos de esta naturaleza. Revisaremos su ámbito de aplicación, con miras a indagar cómo se comporta en la construcción de la regla contractual.

Luego de analizar los términos del contrato del que emerge el conflicto, colegimos que el derecho aplicable para la resolución del fondo de la controversia es la CISG de conformidad a lo preceptuado en su art. $1^{\circ} 1$ ), a) (aplicación directa: ambas partes con establecimiento en Estados signatarios). Esta respuesta habría sido la misma si las partes hubiesen incorporado una cláusula de sometimiento al derecho español o chileno, pues, en ambos ordenamientos la CISG es derecho vigente.

La aplicación de la CISG no requiere pacto expreso, pues ella opera automáticamente a menos que las partes acuerden lo contrario ${ }^{32}$. La doctrina y la jurisprudencia coinciden en orden a que la exclusión de la CISG, según su artículo 6, debe ser concluyente e inequívoca, aun cuando podría no ser expresa $^{33}$, lo que tendrá lugar, por ejemplo, si las partes incorporaran la misma cláusula, pero esta vez sometiéndose a los PECL, o a los $\mathrm{PCCl}$, o al derecho inglés, o al derecho español o chileno excluyendo la CISG o al Código Civil u otro cuerpo de derecho de contratos local ${ }^{34}$. De este modo, concurriendo las condiciones del artículo 1 CISG, el silencio de las partes o la designación del Derecho de un Estado signatario, se activa automáticamente su aplicación. La CISG entonces será, en este caso, el derecho sustantivo aplicable para la resolución del fondo del litigio, eso sí, según lo hemos venido explicando, supletorio de la voluntad de los contratantes.

En este escenario: ¿cómo se configura la regla contractual en la CISG?

En la CISG el contrato es el resultado del cruce de las declaraciones de voluntad de los contratantes, debidamente interpretadas por el árbitro, aplicando

\footnotetext{
32 Hachem Y Schwenzer (2016), pp. 111-115.

${ }^{33}$ Véase FerRARI (2003), pp. 21-38.

${ }^{34}$ ICC Arbitration Case $N^{\circ} 11333$ de 2002, disponible en: http://www.unilex.info/case.cfm?id=1163. Sentencia dictada por Oberlandesgericht Rostock de 10 de octubre de 2001 en causa № 6 U 126/00, disponible en: http://www.unilex.info/case.cfm?id=906.
} 
las reglas de interpretación declarativa ${ }^{35}$ e integradora ${ }^{36}$. Las primeras refieren a la declaración misma (elementos intrínsecos); en cambio, las segundas se centran en el ambiente contractual, en las circunstancias extrínsecas, con la finalidad de completar o desarrollar tales declaraciones, destacándose la disposición que integra al contrato, las prácticas establecidas entre las partes y los usos de comercio ${ }^{37}$.

Así se recoge de los artículos 8 y 9 de la CISG. Veamos:

Artículo 8 (interpretación) ${ }^{38}$.

1) A los efectos de la presente Convención, las declaraciones y otros actos de una parte deberán interpretarse conforme a su intención cuando la otra parte haya conocido o no haya podido ignorar cuál era esa intención.

2) Si el párrafo precedente no fuere aplicable, las declaraciones y otros actos de una parte deberán interpretarse conforme al sentido que les habría dado en igual situación una persona razonable de la misma condición que la otra parte.

\footnotetext{
${ }^{35}$ La función declarativa, según De CASTRO, "es la que corresponde a la interpretación, considerada en sentido estricto" y ella busca atribuir un sentido cierto a la declaración negocial, luego de haber buscado, traducido o explicado lo querido por las partes al contratar. De Castro y Bravo (1985), p. 77.

36 Díez-Picazo, explicando la interpretación integradora nos dice que: "cuando siendo la declaración de voluntad clara, presenta lagunas y hace necesaria una reconstrucción conjetural de la declaración, estableciendo la presunta voluntad hipotética de los propios contratantes" y añade que "La interpretación integradora (...), se distingue nítidamente de la interpretación en sentido estricto, pero ha de distinguirse también de la integración del contrato, porque la integración completa del contrato en aplicación de las normas y reglas ordenadas por las propias fuentes de integración (la buena fe, el uso de los negocios y la ley dispositiva), en tanto la interpretación integradora busca la reconstrucción o el llenado de las lagunas a partir de la propia declaración de voluntad contractual". Dízz-PiCazo (2008), p. 508; VIDAL (2000), pp. 210-211.

37 Siguiendo el modelo de la CISG, el artículo 4.3, de los PCCI (circunstancias relevantes) dispone que: "Para la aplicación de los Artículos 4.1 y 4.2 (determinar la intención común de las partes), deberán tomarse en consideración todas las circunstancias, incluyendo: (...) b) las prácticas que ellas (las partes) hayan establecido entre sí; (...) (f) los usos", con una regla, casi idéntica, el artículo 5.3 (circunstancias relevantes) de los PECL, considera, entre las circunstancias relevantes, la conducta de las partes (b); los usos (f); y la buena fe y la lealtad (g). Y respecto de los usos, los artículos 1.9 de los PCCI y 1.105 de los PECL establecen una regla similar a la del comentado artículo 9 CISG al establecer las condiciones para la incorporación tácita al contrato. Cabe consignar que, en el entorno latinoamericano, siguiendo el modelo del derecho uniforme de contrato, el artículo 964 del Código Civil y Comercial argentino prevé que: "El contenido del contrato se integra con: (...) c) los usos y prácticas del lugar de su celebración cuando sean aplicables porque sean ampliamente conocidos y regularmente observados en el ámbito en que se celebra el contrato, excepto que su aplicación sea irrazonable".

${ }^{38}$ Sobre esta materia, Oviedo (2012), pp. 253-282.
} 
3) Para determinar la intención de una parte o el sentido que habría dado una persona razonable deberán tenerse debidamente en cuenta todas las circunstancias pertinentes del caso, en particular las negociaciones, cualesquiera prácticas que las partes hubieran establecido entre ellas, los usos y el comportamiento ulterior de las partes.

Por su parte, el art. $9^{\circ}$ se refiere a un conjunto de prácticas y usos incorporados al contrato de forma expresa o tácita. El referido precepto señala:

1) Las partes quedarán obligadas por cualquier uso en que hayan convenido y por cualquier práctica que hayan establecido entre ellas.

2) Salvo pacto en contrario, se considerará que las partes han hecho tácitamente aplicable al contrato o a su formación un uso del que tenían o debían haber tenido conocimiento y que, en el comercio internacional, sea ampliamente conocido y regularmente observado por las partes en contratos del mismo tipo en el tráfico mercantil de que se trate.

De la norma transcrita se sigue que las prácticas establecidas entre las partes o los usos convenidos, junto con los usos comerciales ampliamente conocidos (usos internacionales) integran las declaraciones de las partes, desarrollando o completando su contenido como aquello que ha sido querido por las partes.

Para ilustrar sobre el particular pensemos en nuestro caso y, concretamente, en que, respecto de los plazos para el embarque de la fruta, el examen que realiza el comprador y la comunicación de su falta de conformidad, no hay regla expresa en la CISG. Como es sabido, las disposiciones de los artículos 38 (examen de mercaderías) y 39 (comunicación de la falta de conformidad), son de textura abierta, al utilizar expresiones como "tan pronto sea posible" o "plazo razonable". Sin embargo, si asumimos que en el sector del comercio de la fruta es usual que las partes hayan fijado un plazo en otros contratos anteriores fijaron plazos determinados o vengan observando alguno en contratos anteriores y, además, hay usos ampliamente conocidos y aceptados en el sector. Es por lo anterior que, considerando la regla del transcrito artículo 9, si las partes no pactaron un plazo, deberemos estar a las prácticas entre ellas establecidas, las que prevalecerán sobre los usos comerciales. Éstos sólo integrarán el contrato si no hubiere, entre los contratantes, prácticas anteriores. Advertimos, entonces, una prelación de fuentes concurrentes en la configuración de la regla contractual, anteriores a la norma dispositiva o de fondo. Entonces, el orden sería: el acuerdo, que refleja la intención de las partes (subjetiva u objetiva ex art. 8 CISG); las prácticas establecidas entre las 
partes; $y$, finalmente, los usos del tráfico comúnmente aceptados y observados (art. 9 CISG) $)^{39}$.

Sobre la regla de los usos del comercio internacional, hemos de formular dos comentarios. Como señalamos, el art. 28 de la ley modelo exige al árbitro considerar, adicionalmente, los usos comerciales, esto es, los mismos a que refiere el transcrito artículo 9 de la CISG; y el segundo, que estos "usos ampliamente conocidos y regularmente observados" en el comercio internacional, en los términos del citado artículo 9, se entienden como parte integrante de la lex mercatoria, comprendiendo reglas tales como los Incoterms o los mismos $\mathrm{PCCl}^{40}$, siempre y cuando se satisfagan las exigencias o condiciones del artículo $9^{\circ}$ para incorporarlos al contrato, incluso en sentido contrario o alterando las reglas de la CISG.

Como podemos apreciar, la noción de uso comercial, en su función integradora del contrato, es bastante amplia y será el árbitro quien determinará si pueden entenderse aplicables para resolver el conflicto de acuerdo a lo ya expresado, tomando en consideración, en primer lugar, lo señalado por el Derecho de fondo aplicable al caso, en el nuestro, al contenido en la CISG, empero aún queda pendiente si ella contiene la solución expresa respecto de la materia debatida.

\section{Construcción de la regla contractual y resolución del caso}

Advirtiendo que el lugar de arbitraje declarado por las partes es Madrid, veremos si es posible aplicar la Ley de Arbitraje española de 2003 que unifica el régimen del arbitraje interno e internacional, recogiendo la técnica monista, cuyos preceptos, salvo contadas excepciones, se aplican a ambas especies de arbitraje $\mathrm{e}^{41}$.

\footnotetext{
${ }^{39}$ Calvo y Díez-Picazo (1997), p. 144. En el mismo sentido: Schmidt-Kessel (2016), p. 188.

40 Sobre el particular, SCHMidt-Kessel afirman que si bien los Incoterms, los UCP 660 o los PCCI no pueden considerarse, en su conjunto, usos comerciales en los términos del artículo 9 (2) CISG, sus reglas individuales sí pueden serlo, integrando el contrato, siempre que se cumplan las condiciones que el precepto establece. Schmidt-Kessel (2016), pp. 195-196. Por su parte, Bonell reconoce que estos usos comerciales internacionales pueden estar o no contenidos o recogidos por un instrumento formal, citando como ejemplo, los Incoterms. BIANCA y BONELL (1987), pp. 111-113; VIDAL (2003), pp. 993-1041.

${ }^{41}$ Exposición de motivos (II), de la Ley № 60/2003 de 23 de diciembre de 2003, de Arbitraje. Se precisa que "Son pocas y muy justificadas las normas en que el arbitraje internacional requiere una regulación distinta de la del arbitraje interno. Aun con la conciencia de que el arbitraje internacional responde en muchas ocasiones a exigencias distintas, esta ley parte de la base-corroborada por la tendencia actual en la materia- de que una buena regulación del arbitraje internacional ha de serlo también para el arbitraje interno, y viceversa".
} 
El artículo $1^{\circ}$ (ámbito de aplicación), en su numeral 1) dispone que la presente Ley se aplicará al arbitraje comercial internacional ${ }^{42}$. Dispone que el arbitraje será internacional, entre otros casos, si: "a) las partes de un acuerdo de arbitraje tienen, al momento de la celebración del acuerdo, sus establecimientos en Estados diferentes". Seguidamente, la norma -por la extensión de su ámbito de aplicación: arbitraje interno e internacional-, prescribe que: "1. Esta ley se aplicará a los arbitrajes cuyo lugar se halle dentro del territorio español, sean de carácter interno o internacional, sin perjuicio de lo establecido en los tratados que España sea parte o las leyes que contengan disposiciones especiales sobre arbitraje".

Por su parte, el artículo $3^{\circ}$, que reitera el numeral uno del artículo $1^{\circ}$ de la ley modelo, establece entre las circunstancias determinantes para calificar un arbitraje de internacional, si al momento de la celebración del convenio arbitral las partes tienen su domicilio en Estados distintos ${ }^{43}$. Añade, a su vez, otra no prevista en la citada ley: "c) que la relación jurídica de la que dimane la controversia afecte intereses del comercio internacional". De la norma transcrita y de los criterios que ella establece, resulta que la controversia entre el vendedor chileno y el comprador español debe someterse a la ley sobre arbitraje española.

Habiendo precisado que la lex arbitri es española corresponde preguntarse ¿Conforme a qué normas el árbitro resolverá el fondo del litigio?

En relación a este punto, la ley española -alejándose de su modelo- dispone en su art. 34:

1. Los árbitros sólo decidirán en equidad si las partes les han autorizado expresamente para ello.

2. Sin perjuicio de lo dispuesto en el apartado anterior, cuando el arbitraje sea internacional, los árbitros decidirán la controversia de conformidad con las normas jurídicas elegidas por las partes. Se entenderá que toda indicación del derecho u ordenamiento jurídico de un Estado determinado se refiere, a menos que se exprese lo contrario, al derecho sustantivo de ese Estado y no a sus normas de conflicto de leyes.

\footnotetext{
${ }^{42}$ El artículo $1^{\circ}$ de la CISG dispone que para los efectos de su aplicación no se tomará en consideración el carácter comercial o no del contrato, ni de los contratantes. La ley modelo, por su parte, si bien alude a la comercialidad del asunto, entiende esta noción desde una amplia perspectiva, de manera que no debiera existir dudas en la aplicación de la ley arbitral frente a todos los casos de compraventa comercial internacional.

${ }^{43}$ Sobre la internacionalidad en el arbitraje comercial internacional, VÁsQuEZ (2011), pp. 35-40.
} 
Si las partes no indican las normas jurídicas aplicables, los árbitros aplicarán las que estimen apropiadas.

3. En todo caso, los árbitros decidirán con arreglo a las estipulaciones del contrato y tendrán en cuenta los usos aplicables.

De este modo, si las partes no designaron el derecho de fondo, los árbitros aplicarán aquellas normas que se estimen apropiadas al conflicto, apartándose del clásico sistema conflictual que reenvía la solución a una ley estatal. Como señalamos, esta regla tiene especial importancia en el arbitraje internacional, principalmente porque faculta al árbitro para aplicar directamente normas no estatales como ley de fondo, como la "lex mercatoria", sin necesidad de pacto. Así lo prevén los Principios de Unidroit ${ }^{44}$ y los PECL ${ }^{45}$.

También, reviste importancia porque podría entenderse que la disposición vendría a alterar la regla del artículo 7 (2) de la CISG que, ante lagunas o vacíos, ordena su autointegración -a través de los principios generales en que ella se basa- $y$, a falta suya, ordena su heterointegración mediante el derecho interno aplicable según la norma de conflicto. Así, si entendemos que el párrafo segundo del numeral 2 del citado artículo 34 prevalece sobre el citado precepto, el árbitro estaría autorizado para colmar la laguna aplicando la norma que estime más apropiada, que será normalmente de derecho internacional, sobre todo si consideramos que en esta interpretación se debe cumplir con el Ilamado que hace el citado artículo 7 en referencia que, en su párrafo primero, realiza un Ilamado a promover la internacionalidad y uniformidad. Esta misma lectura podría autorizar al árbitro para aplicar la "lex mercatoria" en todo lo no previsto por la CISG, ni resuelto por los principios generales en que ella se basa.

En este contexto, los tribunales arbitrales internacionales deberán aplicar las estipulaciones de las partes y; en su defecto, la ley de fondo que hubieren designado y, en caso de no mediar tal designación, aquella que el árbitro estime más apropiada. En otras palabras, el árbitro deberá resolver el conflicto de fondo con arreglo al contrato, mirado desde dos perspectivas: La primera, relacionada con la ley de fondo que las partes o el árbitro definieron como aplicable; y la segunda, relacionada con la declaración de voluntad de las

\footnotetext{
${ }^{44}$ En el preámbulo de los PCCI (2010), se lee: "Estos Principios pueden aplicarse cuando las partes no han escogido el derecho aplicable al contrato" y antes declaran que: "Estos Principios pueden aplicarse cuando las partes hayan acordado que su contrato se rija por principios generales del derecho, la 'lex mercatoria' o expresiones semejantes".

${ }^{45}$ Una regla idéntica a la de los PCCI la encontramos en el artículo 1:101 (Application of the Principles), (3), b) y a).
} 
partes. En otras palabras, el árbitro debe resolver el litigio de fondo conforme al contrato y las normas que se superponen al mismo o suplen sus silencios.

Habiendo precisado estas dos perspectivas, la necesidad de configuración interna del contrato nos lleva a la construcción de la regla contractual, la que implica distinguir dos niveles: el acuerdo -la declaración de las partes- y las normas de fondo aplicables ${ }^{46}$. Llegados a este punto, la pregunta que aquí subyace es qué debemos entender por contrato. Consideramos que este instrumento debemos entenderlo en ambas dimensiones, su contenido -que va más allá de derechos y obligaciones- ${ }^{47}$, pues comprende ${ }^{48}$ :

a) Las estipulaciones de las partes debidamente interpretadas según los criterios contenidos en la normativa que resulte aplicable;

b) Los usos y prácticas que se entienden también como una manifestación de un acuerdo tácito de las partes.

c) Normas dispositivas, que integran el silencio de la voluntad ya interpretada. La labor de integración presupone el agotamiento de la interpretación de las declaraciones de las partes ${ }^{49}$.

d) Normas imperativas que se encontrarán por sobre la voluntad de las partes.

En esta configuración, quedan en evidencia como se entrelazan los acuerdos de voluntad y los sistemas normativos, lo que permite la configuración de la denominada "regla contractual" que contiene el precepto fundante de la decisión arbitral. El primero, el acuerdo -interpretado y, como diremos, desarrollado por las prácticas y los usos-; y, el segundo, la norma sustantiva o de fondo aplicable ${ }^{50}$.

Las normas antes señaladas (b y c) serán, en definitiva, las normas de fondo elegidas por las partes o elegidas por el árbitro de acuerdo a lo ya indicado. En el caso revisado, estas normas corresponden a la Convención de Viena

${ }^{46}$ VIDAL (2000), pp. 209-227.

47 Se supera la comprensión tradicional de vinculación contractual entendida como conjunto de obligaciones y deberes, transitando a una más objetiva y eficiente, de garantía de la realización del contrato, de satisfacción del interés de las partes en cuanto acreedoras. Véase: Morales Moreno (2016), pp. 82-83.

${ }^{48}$ Se entiende que las normas imperativas son un presupuesto de la validez del contrato, de manera que -más que integrar la regla contractual- se deben observar para su eficacia.

${ }^{49}$ En opinión de Caffarena Laporta, el resultado que alcance la interpretación de la declaración contractual, representa el querer de las partes y prevalece sobre la norma supletoria o dispositiva, excluyendo o limitando su vigencia. Ella sólo la conservará en lo no previsto, integrando la declaración. Caffarena (1985), p. 923.

50 Sin perjuicio de que las partes hubieren designado al árbitro en calidad de arbitrador o amigable componedor, que no es la hipótesis que nos interesa ahora. 
sobre compraventa internacional de mercaderías que, a su vez, se integra por los principios Unidroit y los usos comerciales internacionales. Corresponde ahora apreciar cómo se comporta esta regla.

Como indicamos, en el caso planteado las declaraciones de las partes no dan una respuesta expresa en las estipulaciones de su contrato, en orden a determinar la solución del conflicto, esto es, si hubo o no falta de conformidad, más aun, no existe referencia sobre sus condiciones y límites.

No hemos de olvidar que el contrato es un dispositivo que prevé no sólo para el cumplimiento, sino también para el incumplimiento, al contener todo un entramado encaminado a que el acreedor -en este caso el compradoralcance la satisfacción de su interés. Nos referimos a los remedios que las partes pueden modular según sus propios intereses o que son los que prevé la norma que integra el contrato. En nuestro caso tal entramado es el de la CISG, particularmente, aquel previsto por sus artículos 45 y siguientes.

El art. 6 de la CISG reconoce la libertad de pacto en su mayor expresión, facultando a las partes para modificar sus disposiciones y/o excluirlas ${ }^{51}$, de modo que, sólo si no se excluye o modifica la norma uniforme, ésta integrará la regla contractual ${ }^{52}$. Entonces, frente a la ausencia de declaración o pacto, cobra toda su vigencia la norma dispositiva de la CISG que integra los vacíos de la voluntad de las partes, permitiendo al árbitro concluir correctamente su tarea de construcción de la regla contractual, con arreglo a la cual dirimirá o resolverá el fondo del conflicto ${ }^{53}$. El dispositivo contractual, así concebido, permitirá contrastar lo idealmente convenido por las partes y lo efectivamente ejecutado, en este caso, por el vendedor, con la finalidad de definir si hubo incumplimiento y sus efectos para el caso concreto.

Habiendo hecho estas precisiones, la cuestión que queda por despejar es si, en este caso concreto, ¿la CISG resuelve el asunto controvertido, permitiendo al árbitro resolver el fondo del mismo o no? ${ }^{54} \mathrm{El}$ asunto es si procede la pretensión de sustitución de las mercaderías a que alude el artículo 46 (3) CISG, está sometida o no al límite de los costes excesivos o desproporcionados. La respuesta es negativa, la CISG no establece, en general, ese límite a

\footnotetext{
51 Oviedo (2011), p. 44.

52 HaChem (2016), pp. 38-39.

53 En doctrina, para evitar confusión entre la función integradora de la interpretación y la integración por medio de la norma dispositiva, se ha acuñado el término "heterointegración", en oposición a la "autointegración" (función interpretativa). Así, LACRUZ emplea el vocablo "heterointegración" aludiendo a la hipótesis de vacíos contractuales originados por la carencia de una regulación privada y que se suplen con las fuentes externas (...). LaCruz (1994), pp. 529-533.
}

54 Oviedo (2014), pp. 219-253; Vidal y Oviedo (2016), pp. 153-185. 
la procedencia del cumplimiento específico, a diferencia de prácticamente todos los instrumentos no estatales (soft law) y las más recientes reformas en materia de contratos ${ }^{55}$. Recordemos que el artículo 7 (2) dispone que, si un asunto comprendido en el ámbito material de la CISG no está expresamente resuelto por sus disposiciones, procede la aplicación de los principios generales en que se basa la CISG y, de no existir alguno que resuelva el punto, el derecho interno aplicable de acuerdo con la regla de conflicto del derecho internacional privado. En el caso en cuestión el comprador recibió las mercaderías, las examinó y comunicó al vendedor oportunamente su falta de conformidad y, conjuntamente, ejerció la pretensión de sustitución de las mercaderías de acuerdo al art. 46 (3) CISG, comunicándolo tal como lo exige la norma. Por su parte, el vendedor se opuso a la pretensión de sustitución porque el cumplimiento específico -la sustitución ex art. 46 (3) CISG- le imponía unos costos excesivos, en circunstancias que era razonable que el comprador resolviera el contrato y celebrara una compra de reemplazo, lo que no hizo. El comprador, frente a esta oposición, fundada en tal argumento, insistió y activó la cláusula arbitral para resolver el conflicto, esgrimiendo, como fundamento, que la CISG establece como única condición para la procedencia de la sustitución, que la falta de conformidad sea esencial y este era el caso según lo dispone el art. 25 CISG.

Para resolver este punto el árbitro debe dar respuesta al siguiente interrogante: ¿está o no en lo correcto el comprador? La CISG, a diferencia del régimen de la reparación de las mercaderías no exige como condición que la sustitución sea razonable atendidas las circunstancias (art. 46 (2) CISG), sino únicamente que el incumplimiento sea esencial (art. 25). Entendemos que si bien la CISG resuelve esta materia, no lo hace cabalmente, de manera que la norma habrá que integrarse de acuerdo a lo dispuesto por el artículo 7 (2); en tal sentido, el árbitro primeramente debe buscar la solución en uno de los principios generales en que se basa la CISG, que en el caso podría ser el principio de lo razonable que, para la pretensión de cumplimiento específico, adquiere forma en el artículo 7.2.2. PCCI que establece, para la pretensión de cumplimiento específico de obligaciones no dinerarias, un límite económico (art. 7.2.2., b) y c)). Esta regla daría forma y contenido al principio general citado, integrando el vacío del art. 46 (3) antes citado, configurando la regla contractual y resolviendo el caso en cuestión.

${ }_{55}$ Para un examen del límite económico de la pretensión de cumplimiento específico en el derecho uniforme y armonizado de contratos y su posible construcción en Chile, véase: VIDAL (2015), pp. 555-578. 
El recurso a esta regla permitiría limitar el ejercicio de la pretensión de sustitución por resultar, atendidas las circunstancias, excesivamente costosa para el vendedor, dado que era razonable y menos costoso celebrar una operación de reemplazo ${ }^{56}$.

¿Qué ocurre si el árbitro no alcanza la convicción acerca de que este principio general o cualquier otro en que se basa la CISG introduzcan un límite económico a pretensión de sustitución? ¿Cómo se suple la laguna? En nuestra opinión, si estamos al tenor de lo dispuesto en el artículo 7 (2) en comento, el árbitro debiera aplicar el derecho interno según la norma de conflicto. El problema es que, el posible derecho aplicable para integrar la laguna -el chileno o el español-, no reconocen en general, ni el derecho a la sustitución, ni menos la existencia de un límite económico a esta pretensión, Por consiguiente, conforme la regla de integración del artículo 7 (2), ninguno de estos ordenamientos soluciona expresamente el asunto.

En este caso surge una nueva pregunta: ¿Podría el árbitro, conforme con el art. 34 de la ley española de arbitraje, Ilegar a una solución diversa, aplicando, para integrar la laguna denunciada, aquel Derecho que le parezca más conveniente? Si consideramos que la CISG es el derecho sustantivo aplicable al caso, al no haber sido excluida por las partes según su art. $6^{\circ}$, la respuesta sería negativa. En la CISG debiéramos encontrar la solución al problema suscitado entre las partes; sin embargo, como hemos dicho, en este punto guarda silencio y como las partes en el contrato no fijaron derecho sustantivo en complemento de la CISG -para integrar sus lagunas-, debemos echar mano a la solución del artículo 7(2) citado, aplicando el derecho interno según la regla de conflicto. Con todo, la colisión normativa entre el citado artículo 37 y el art. 7 (2) es más aparente que real, principalmente porque ambas disposiciones se sitúan en planos distintos, debiendo prevalecer la CISG, por mucho que la solución que ella ofrezca para esta hipótesis no resulte más adecuada, la del recurso al sistema conflictual del derecho internacional privado y subsecuente aplicación de un derecho interno ajeno a la realidad del comercio internacional.

En otros términos, el art. 7 (2) desplazaría la regla del art. 37, de manera que debemos considerar los principios generales y, en subsidio de los mismos, el derecho nacional que corresponda de acuerdo con las normas de conflicto.

En caso de que no existan principios que se refieran a la materia, ni las normas estatales planten solución, existen dos alternativas: rechazar la defensa del vendedor y condenarle a la sustitución de las mercaderías o, si es el caso,

${ }^{56}$ VIDAL (2005), pp. 55-88. 
a su equivalente pecuniario por aplicación de la norma de ejecución del laudo; o dar un paso atrás y volver a la regla de configuración del acuerdo de las partes según el art. 9 CISG que, como sabemos, ordena la incorporación de los usos comerciales internacionales y dilucidar si es posible construir el límite a la pretensión de sustitución con apoyo en tales usos, asignándole la consideración de tal al art. 7.2.2. PCCI. Tal precepto no aplica por no representar un principio general en que se basa la CISG, ni tratarse del derecho más conveniente, sino que se encuentra en un estadio anterior, es decir, como uso comercial en función integradora del contrato. El árbitro podrá fundar esta vía de solución, invocando la necesidad de interpretar la CISG teniendo en cuenta su carácter internacional y la necesidad de promover la uniformidad en su aplicación y de asegurar la observancia de la buena fe en el comercio internacional (art. 7 (1) CISG).

En resumen, el árbitro deberá construir la regla contractual a partir de la declaración de las partes debidamente interpretadas y desarrolladas (arts. 8 y 9) y, en todo lo no previsto, deberá integrar tal voluntad por la CISG. Si el problema que surge entre las partes -procedencia o no de la pretensión de sustitución- no está expresamente resuelto por la CISG, hemos de recurrir a los principios en que ella se basa y, a falta de ellos, al derecho interno si nos apegamos al tenor del artículo 7 (2) CISG. Si el árbitro tiene facultades como arbitrador, podrá obviar las normas antes mencionadas y resolver en equidad, sin llegar a desatender el tenor e interpretación del contrato, sus estipulaciones y usos comerciales (artículo 34 Ley de Arbitraje).

De este modo, Ilegamos a la conclusión de que la regla contractual, así concebida, (voluntad interpretada y leyes aplicables), es fundamental al representar el dispositivo conforme el cual el árbitro resolverá el conflicto, pues se trata de un instrumento que prevé para el cumplimiento y el incumplimiento.

\section{Conclusiones}

La resolución de una controversia contractual exige al juez o árbitro que conoce de ella la labor de develar el contenido de las estipulaciones contractuales y las normas que regirán el conflicto, lo que le obligará a realizar una labor de "construcción de la regla contractual". Este conjunto será el fundamento conforme con el cual el juez o árbitro acogerá o rechazará la pretensión objeto del juicio respectivo.

En cuanto al contenido del contrato debemos distinguir la voluntad expresada por las partes por medio de sus estipulaciones, y también las prácticas y usos del comercio incorporados por aplicación del principio de la buena fe. Además deben delimitarse las normas aplicables que se superponen, integran o suplen los vacíos de esa voluntad debidamente interpretadas. Estos 
son los elementos que nutren al contrato y que permiten configurar la regla contractual.

En el presente artículo, nos hemos detenido en un caso particular de compraventa donde resulta aplicable la Convención de Viena sobre Compraventa Internacional de Mercaderías, en que debimos prestar especial atención a los elementos interpretativos e integrativos que ella contiene respecto del contrato, junto con cada una de las leyes que el árbitro debía considerar en su ejercicio reflexivo.

De no efectuar esta labor de forma descrita, no solo se llegará a un resultado inadecuado, sino que el laudo podrá ser anulado por algunas de las causales descritas en la lex arbitri, que a su vez se vinculan con las leyes aplicables. De este modo, el árbitro internacional debe tomar en consideración cada una de las variables aquí explicadas en favor de realizar una debida labor.

\section{BiBLIOGRAFÍA CITADA}

Berger, Klaus (2007): "Re-examining the Arbitration Agreement: Aplicable LawConsensus or Confusion?", en: Van den Ber, Albert (editor), International Arbitration, 2006: Back to Basics? ICCA Congress Series 2006 (Kluwer Law International), pp. 301-334.

BianCA, C.M. y BonelL, M.J. (1987): Commentary on the International Sales Law: The 1980 Vienna Sales Convention (Milán, Ed. Giuffrè).

Caffarena Laporta, Jorge (1985): "El requisito de identidad del pago en las obligaciones genéricas", en: Anuario de Derecho Civil (Año 4, № 38), p. 923. Calvo Caravaca, Alfonso (2009): "El reglamento Roma I sobre la ley aplicable a las obligaciones contractuales: Cuestiones Escogidas", en: Cuadernos de Derecho Transnacional (Vol. 1, № 2), pp. 60-61.

Calvo Caravaca, Alfonso y Carrascosa González, Javier (2009): La ley aplicable a los contratos internacionales: el Reglamento Roma I (Madrid, Ed. Colex).

Castellanos Ruiz, Esperanza (2009): El Reglamento Roma I sobre la ley aplicable a los contratos internacionales y su aplicación por los tribunales españoles (Granda, Ed. Comares).

De Castro y Bravo, Federico (1985): El negocio jurídico (Madrid, Civitas).

De Miguel Asensio, Pedro (2011): "Contratación Comercial Internacional", en: A.A. V.V, Derecho de los negocios internacionales, $3^{\text {a }}$ edición (Madrid, Ed. lustel), p. 317.

Díez-Picazo, Luis (1997): La compraventa internacional de mercaderías, Comentario de la Convención de Viena (Madrid, Ed. Civitas). 
Díez-PICAzo, Luis (2008): Fundamentos del derecho civil (Madrid, Civitas, 2008), Tomo I.

Feldstein de Cárdenas, Sara (1995): Contratos internacionales. Contratos celebrados por ordenador. Autonomía de la voluntad. Lex mercatoria (Buenos Aires, Abeledo Perrot).

Fernández Rozas, José (2007): "Determinación del lugar de arbitraje y consecuencias del control del laudo por el tribunal de la sede arbitral", en: Lima-arbitration; Revista del Círculo Peruano de Arbitraje (No 2), pp. 25-62.

Fernández Rozas, José Carlos; Arenas García, Rafael y De Miguel Asensio, Pedro (2005): Derecho de los negocios internacionales (Madrid, Ed. lustel).

FerRARI, Franco (2004): "The CISG's sphere of application: Articles 1-3 and 10", en: Ferrari; Franco; Flechtner, Harry y Brand, Ronald (editors), The Draft UNCITRAL Digest and Beyond: Cases, Analysis and Unresolved Issues in the U.N. Sales Convention (Londres, Sweet \& Maxwell), pp. 21-95.

HaChem, Pascal y Schwenzer, Ingeborg (2016): "Artículo 60", en: SCHwenzer, Ingeborg (editor), Commentary on the UN Convention on the International Sale of Goods (CISG), $4^{\circ}$ edition (Oxford, Ingeborg Schwenzer Ed.), pp. 111-115.

Hachem, Pascal, (2016): "Artículo 10", en: Schwenzer, Ingeborg (editor) Commentary on the UN Convention on the International Sale of Goods (CISG), $3^{\text {a }}$ edition (Oxford University Press), pp. 38-39.

Jacquet, Jean Michel; DelebeCque, Philippe y Corneloup, Sabine (2010): Droit du commerce international, segunda edición (París, Ed. Dalloz).

KASSIS, Antoine (1984): Théorie générale des usages de commerce: droit comparé, contrats et arbitrage internationaux, lex mercatoria (París, Librairie générale de droit et de jurisprudence).

Lacruz Berdejo, José Luis (1994): Elementos de Derecho Civil, tercera edición (Barcelona, Ed. Bosch, Tomo II.

LAGARDE, Paul (1987): "Approche critique de la lex mercatoria", en: Le droit des relation économiques internationales (Études offertes à Bethold Goldman) (Paris, Litec.), pp. 125 y ss.

LeIBLE, Stefan (1999): "La importancia de la autonomía conflictual para el futuro del derecho de los contratos internacionales", en: Cuadernos de Derecho Transnacional (Vol. 3, № 1), pp. 217-218.

Leible, Stefan (2010): "La importancia de la autonomía conflictual para el futuro del derecho de los contratos internacionales", en: Espinosa, Leonardo, Estudios sobre el derecho de los contratos internacionales (Bogotá, U. Sergio Arboleda), pp. 13-47. 
López de Argumedo, Álvaro; Piñelro, Luis (2011): “El juez de apoyo en la nueva legislación arbitral francesa", en: Spain arbitration review: Revista del Club Español de Arbitraje (№ 11), pp. 109-125.

Marella, F. (2005): "Autonomía privata e contratti internazionali", en: Autonomia contrattuale e diritto privato europeo, a cura di Gianluca Sicchiero (Milán, Cedam), p. 224.

Merino Merchán, José (2002): "Ley aplicable al contrato arbitral", en: Revista de Contratación Electrónica ( $\left.N^{\circ} 30\right)$, pp. 25-38.

Morales Moreno, Antonio (2016): Claves de la modernización del Derecho de los Contratos (Bogotá, Grupo Editorial Ibáñez Centro de Estudios de Derecho Comparado).

Oppetit, Bruno (2006): Teoría del arbitraje (Santiago, Ed. Legis).

Oviedo Albán, Jorge (2011): Estudios sobre Compraventa internacional de Mercaderías. Aplicaciones jurisprudenciales (Madrid, Ed. Académica Española).

Oviedo Albán, Jorge (2012): "El carácter internacional y la interpretación uniforme de la Convención de Naciones Unidas sobre Compraventa Internacional de Mercaderías", en: Boletín mexicano de derecho comparado (Vol. 45, No 133), pp. 253-282.

Oviedo Albán, Jorge (2014): "La protección del comprador por falta de conformidad material en la compraventa internacional de mercaderías", en: Revista de Derecho Privado, Universidad del Externado de Colombia (No 26), pp. 219-253.

SÁnchez Calero, Sixto (2009): "Derecho aplicable al fondo de la controversia en el arbitraje comercial internacional", en: Revista Española de Derecho Internacional (Año 1, № 61).

Schmidt-Kessel, Martin (2005): "Artículo 9", en: Schlectriem \& Schwenzer, Commentary on the UN Convention on the International Sale of Goods (CISG), pp. 195-196.

SChwenzer, I.; HaChem, P. (2016): "Artículo 96", en: Commentary on the UN Convention on the International Sale of Goods (CISG), cuarta edición (Oxford, Ingeborg Schwenzer Ed.).

Silva Romero, Eduardo (2008): El contrato de arbitraje (Bogotá, Ed. Legis).

TAleRo RuedA, Santiago (2008): Arbitraje comercial internacional; instituciones básicas y derecho aplicable (Bogotá, Ediciones Uniandes-Editorial Temis). 
VÁsquez Palma, María Fernanda (2011): "Relevancia de la sede arbitral y criterios que determinan su elección", en: Revista Chilena de Derecho Privado (No 16), pp. 77-137.

VÁsquez Palma, María Fernanda (2011): Arbitraje en Chile. Análisis crítico de su normativa y jurisprudencia (Chile, Ed. Abeledo Perrot).

VÁsquez Palma, María Fernanda (2017): Contratación y Arbitraje Internacional, Temas relevantes (Bogotá, Ed. Ibáñez).

Vidal Olivares, Álvaro (2000): "La construcción de la regla contractual en el derecho civil de los contratos", en: Revista de Derecho de la Pontificia Universidad Católica de Valparaíso ( No 21), pp. 211 y 219.

Vidal Olivares, Álvaro (2003): “La función integradora de los principios generales en la compraventa internacional de mercaderías y los principios de la Unidroit sobre contratos comerciales internacionales", en: Anuario de Derecho Civil (No 61), pp. 993-1041.

Vidal Olivares, Álvaro (2005): “Atribución y exoneración de responsabilidad en la compraventa internacional: Construcción de las reglas a partir del artículo 79 de la Convención de Viena", en: Revista de Derecho (Valdivia) (Vol. 18, № 1), pp. 55-88.

Vidal Olivares, Álvaro (2015): "La pretensión de cumplimiento específico de las obligaciones no dinerarias y los costes excesivos para el deudor como límite a su ejercicio", en: Estudios de Derecho Civil IX (Chile, Ed. LegalPublishing Thomson Reuters), pp. 555-578.

Vidal Olivares, Álvaro y Oviedo Albán, Jorge (2016): “Riesgo de las mercaderías en la compraventa internacional. Una aproximación desde el incumplimiento y los remedios del comprador", en: Revista Derecho Privado (No 31), pp. 153-185.

\section{NORMAS JURÍDICAS CITADAS}

Ley $N^{\circ}$ 60/2003, de Arbitraje. Boletín Oficial español No 309, de 26 de diciembre de 2003.

Ley Modelo de la CNUDMI sobre Arbitraje comercial internacional. Cnudmi, 1985.

Ley № 26.994, Código Civil y comercial de Argentina, de 7 de octubre de 2014.

\section{JURISPRUDENCIA CITADA}

Sentencia dictada por Oberlandesgericht Rostock de 10 de octubre de 2001 en causa $N^{\circ} 6 \cup$ 126/00, disponible en: http://www.unilex.info/case. $\mathrm{cfm}$ ? id=906. 
Court of Appeal, Sudamerica Cia. Nacional de Seguros S.A. v. Enesa Engenharia S.A. (2012) EWCA Civ. 638, 16 de mayo de 2012.

Caso English Commercial Court, Arsanova Ltd., \& Ors v. Cruz City I Mauritius Holdings (2012) EWHC 3702 (Comm), 20 de diciembre de 2012.

ICC Arbitration Case № 11333, disponible en: http://www.unilex.info/case. cfm?id=1163. 
